\title{
PERANCANGAN DAN PEMBUATAN MESIN LAS ELEKTRODA GANDA UNTUK MENINGKATKAN KUALITAS HASIL LAS
}

\author{
Yustiasih Purwaningrum $^{1}$, Medilla Kusriyanto ${ }^{2}$, Rudi Kurniawan ${ }^{3}$ \\ Jurusan Teknik Mesin ${ }^{1}$, Jurusan Teknik Elektro ${ }^{2}$, \\ Fakultas Teknologi Industri Universitas Islam Indonesia ${ }^{1,2)}$ \\ Jl. Kaliurang KM. 14.5, Sleman, Yogyakarta, 55501 \\ Email :yustiasih.purwaningrum@uii.ac.id ${ }^{I}$,Medilla@uii.ac.id ${ }^{2}$
}

\begin{abstract}
Double Metal Arc Welding Gas Electrodes (DE-GMAW) is a new welding process that separates the melting current into a base metal current and a controlled current by adding a TIG torch to a conventional GMAW system to form an alternative path that will flow through the current. This makes it possible to reduce the current passing through the base metal, so that the heat input in the base metal can be controlled at the desired level. Research has been done to know the parameters for the welding process run stable between welding wire and torch TIG as current cutter. Parameters that affect the stability of the control system are Bypass Electrodes, Tungsten Distance to Welding Electrodes, Tungsten Distance to Workpieces, Torch GMAW Tube Distance to Workpieces, Angles between Tungsten and Welding Wires. To control the base metal current at the desired level, a group of power resistors is added in the control system. In this study, the welding is done using $18 \mathrm{~V}$ voltage by using several variations of the number of resistors. From the research shows that the control system developed can adjust the current cut in a large range to maintain the base metal current at the desired level. The welding results using the DE-GMAW control system show the physical properties of the weld result better when compared with welding without using current control system.
\end{abstract}

Keywords : GMAW, DE-GMAW.

\section{PENDAHULUAN}

Pengelasan adalah proses bergabungnya dua bahan. Proses pengelasan lebih ekonomis dan prosesnya lebih cepat dari pengecoran, jika proses pengelasan tidak dioptimalkan dengan parameterparamater proses pengelasan, tegangan sisa akan berkembang dalam struktur. Parameter - paramater proses pengelasan yaitu tegangan, gas pelindung, arus las, kecepatan las, gap akar, laju alir gas pelindung yang telah dikombinasikan. Di antara pengelasan busur lainnya, Gas Metal Arc Welding (GMAW) yang digunakan telah meningkat ditahun - tahun terakhir karena fleksibilitas yang ada pada las GMAW. Geometri manik las yang dihasilkan oleh las busur memiliki peran penting dalam menentukan sifat mekanik dan kualitas las. Pada tahun 2007 2011, di Indonesia persentase faktor penyebab kecelakaan laut dengan kesalahan teknis adalah 59\%. Struktur kapal berkaitan erat dengan proses produksi desain dan kapal. Hampir 90\% dari kegagalan struktur teknik yang paling sering gagal adalah struktur konsentrasi tegangan, di mana yang 36\% merupakan dari kegagalan sambungan las (Yustiasih, 2016).

Dalam beberapa tahun terakhir, beberapa proses pengelasan baru seperti las kembar tandem dan pengelasan laser-MIG hybrid dikembangkan untuk meningkatkan produktivitas yang lebih tinggi. Meskipun kemajuan telah dicapai secara signifikan, semua proses ini memiliki masalah yang sama yaitu masukan tambahan panas pada logam dasar. Secara umum, produktivitas yang lebih tinggi memerlukan lebih banyak logam pengisi yang menuntut arus lebur yang lebih tinggi dari proses pengelasan. Pada sebagian besar kasus, arus leleh maksimum pada proses pengelasan tertentu adalah tetap untuk bagian pekerjaan karena geometri tetap dari benda kerja. Arus pengelasan tidak bisa melampaui batas maksimum agar tidak membakar logam 
dasar. Akibatnya, persyaratan produktivitas yang lebih tinggi dan pembatasan arus leleh maksimum menjadi dilema bagi para peneliti. Untuk mengatasi dilema ini, GMAW (Gas Metal Arc Welding) dimodifikasi menjadi sistem DE-GMAW. DE-GMAW (Double Elektroda Gas Metal Arc Welding) adalah proses GMAW yang dimodifikasi dengan membagi arus leleh kedalam arus logam dasar dan kedalam pemotong arus dengan menambahkan torch pemotong ke sistem GMAW konvensional untuk membangun busur pemotong.

\section{TINJAUAN PUSTAKA}

Pengelasan GMAW (Gas Metal Arc Welding) adalah proses utama untuk penggabungan logam. GMAW adalah suatu metode pengelasan dimana gas disemburkan ke daerah yang dilas untuk melindungi busur, elektroda dan logam induk yang mencair terhadap pengaruh udara luar. Gas pelindung yang dipakai adalah gas yang tidak mudah bereaksi baik terhadap udara luar maupun logam yang mencair. GMAW konvensional biasanya menggunakan polaritas balik atau DCRP (Direct Current Reverse Polarity) dimana benda kerja dihubungkan pada posisi negatif (-) dari mesin las dan elektroda dihubungkan pada posisi positif (+) dari mesin las. Gas Metal Arc Welding (GMAW), kadang - kadang disebut Metal Inert Gas (MIG) welding atau Metal Active Gas (MAG) welding (Muku, 2009).

Berdasarkan penelitian yang dilakukan oleh Li, dkk (2007) sebuah sistem GMAW double - elektroda dikembangkan dengan menambahkan elektroda tungsten non consumable dalam sistem GMAW konvensional untuk membentuk loop bypass. Kondisi untuk membangun dan menjaga proses yang stabil diperoleh melalui eksperimen.
Sistem ini menggunakan kelompok daya resistor yang dikendalikan oleh IGBTs untuk mendapatkan pengambilan arus yang berbeda. Sebuah model telah digunakan untuk mengkorelasikan perubahan perlawanan yang diperlukan untuk mencapai arus logam dasar yang diinginkan untuk deviasi dari arus logam dasar dari level yang diinginkan. Percobaan di verifikasi bahwa sistem kontrol yang dikembangkan dapat menjamin cepat waktu yang cukup konstan untuk DE-GMAW dan saat memotong arus dapat disesuaikan untuk mempertahankan arus dasar logam yang diinginkan dalam kisaran arus total yang relatif luas.

\subsection{Arduino UNO R3}

Menurut Banzi (2008) arduino didefinisikan sebagai sebuah platform komputasi fisik (Physical Computing) yang open source, yang terdapat pada board input output sederhana. Platform komputasi fisik sendiri mempunyai makna yang berarti sebuah sistem fisik yang interaktif dengan penggunaan software dan hardware yang dapat mendeteksi dan merespon situasi dan kondisi yang ada didunia nyata. Nama Arduino tidak hanya dipakai untuk menamai board rangkaiannya saja, tetapi juga untuk menamai bahasa dan software pemrogramannya, serta lingkungan pemrograman atau IDE-nya, Integrated Development Environment.

\subsection{Sensor Arus ACS758}

Sensor arus ACS758 terdiri dari presisi low - offset linear Hall circuit dengan jalur konduksi tembaga yang terletak di dekat die. Terapan arus yang mengalir melalui jalur konduksi tembaga ini menghasilkan medan magnet dimana IC Hall mengubah menjadi tegangan proporsional, akurasi perangkat dioptimalkan melalui sinyal magnetik ke transduser Hall. 
Tegangan output proporsional yang tepat disediakan oleh Low - offset, chopper stabilized BiCMOS Hall IC, yang mana diprogram untuk akurasi dipabrik.

ACS758 mengeluarkan sinyal analog, Vout yang bervariasi secara linear dengan arus sampel utama $\mathrm{AC}$ atau $\mathrm{DC}$, dalam kisaran yang ditentukan. $\mathrm{CF}$ adalah untuk manajemen noise yang optimal, dengan nilai yang bergantung pada aplikasi. Gambar 1 merupakan diagram perancangan sensor arus yang dilengkapi rangkaian low pass filter.

\subsection{MOSFET}

MOSFET (Metal Oxide Semiconductor Field Effect Transistor) adalah suatu transistor dari bahan semikonduktor (silikon) dengan tingkat konsentrasi ketidakmurnian tertentu. Tingkat dari ketidakmurnian ini akan menentukan jenis transistor tersebut, yaitu transistor MOSFET tipe-N (NMOS) dan transistor MOSFET
tipe-P (PMOS). Bahan silicon digunakan sebagai landasan (substrat) dari penguras (drain), sumber (source), dan gerbang (gate).

Selanjutnya transistor dibuat sedemikian rupa agar antara substrat dan gerbangnya dibatasi oleh oksida silikon yang sangat tipis. Oksida ini diendapkan di atas sisi kiri dari kanal, sehingga transistor MOSFET akan mempunyai kelebihan dibanding dengan transistor BJT (Bipolar Junction Transistor), yaitu menghasilkan disipasi daya yang rendah.

Pada rangkaian sistem DE-GMAW ini terdiri dari dua bagian utama yaitu susunan rangkaian MOSFET dan susunan rangkaian resistor. Pada rangkaian MOSFET terdiri dari tiga sumber daya yang berasal dari output gate driver masing - masing bertegangan 12 Volt. Susunan rangkaian MOSFET dan resistor dapat dilihat pada gambar 2.

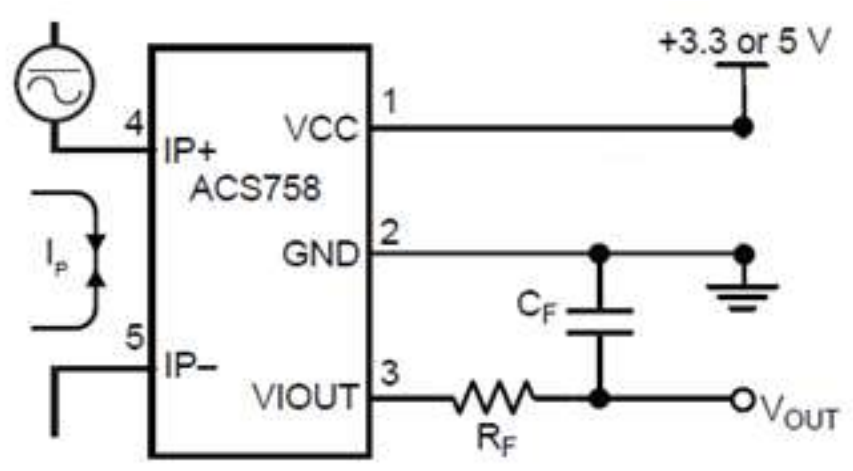

Gambar 1. Rangkaian Sensor Arus dan Lowpass Filter.

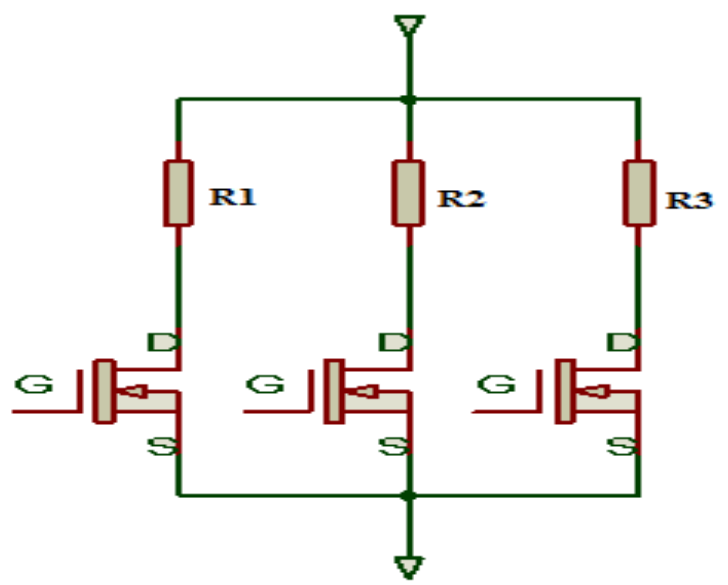

Gambar 2. Rangkaian MOSFET dan Resistor 


\subsection{Gate Driver MOSFET}

Rangkaian gate driver berfungsi sebagai penghubung antara sinyal dari prosesor dan sinyal yang mengontrol potensial tegangan titik $\mathrm{G}$ (gate) terhadap $\mathrm{S}$ (source) pada MOSFET sehingga bisa mengoperasikan MOSFET dengan referensi tegangan yang tepat, tegangan tersebut bernama Voltage Gate to Source atau disingkat VGS. Rangkaian gate driver berfungsi sebagai saklar yang mengirimkan muatan menuju MOSFET utama ataupun mengambil muatan untuk mematikan MOSFET utama.

TLP 250 merupakan IC khusus yang digunakan sebagai gate driver MOSFET dengan metode isolated gate drive. TLP 250 jenis optocoupler yang cocok untuk gate drive MOSFET dengan operasi tegangan tinggi sesuai yang dibutuhkan untuk melakukan kemudi MOSFET. TLP250 terdiri dari LED optik sebagai transmiter dan receiver yang digabungkan dengan sirkuit terpadu memungkinkan bekerja pada frekuensi tinggi. Rangkaian gate driver MOSFET ditunjukkan pada gambar 3.

\subsection{Konstruksi Torch DE-GMAW}

Aplikasi konstruksi Torch DE-GMAW ditunjukan pada gambar 4, perancangan konstruksi berdasarkan percobaanpercobaan yang telah dilakukan. jarak horizontal dari ujung tungsten ke ujung elektroda las optimal untuk menciptakan busur yaitu pada jarak $4 \mathrm{~mm}$, telah dilakukan percobaan pada jarak $2 \mathrm{~mm}$ dan $5 \mathrm{~mm}$. Namun jarak yang terlalu dekat akan menghalangi masuknya lelehan elektroda ke dalam sambungan las dan jarak yang terlalu jauh mengakibatkan tidak terjadinya busur pemotong arus, sehingga arus tidak dapat terkontrol.

Jarak antara tungsten elektroda dan benda kerja optimal pada jarak $6 \mathrm{~mm}$, jarak yang lebih kecil dari $6 \mathrm{~mm}$ mengakibatkan tungsten lengket pada lelehan elekroda filler, jarak yang terlalu tinggi mengakibatkan tidak terjadinya busur pemotong arus. Jarak tabung torch GMAW ke benda kerja yang optimal adalah sekitar 10 - $15 \mathrm{~mm}$, telah dicoba pada jarak $20 \mathrm{~mm}$. Namun, jarak yang terlalu jauh mengakibatkan gas pelindung menyebar dan tidak terpusat pada busur pengelasan. Sehingga lelehan logam las akan terkontaminasi udara dan warna lelehan logam las berwarna hitam karena lelehan logam las tidak terlindungi dengan sempurna.

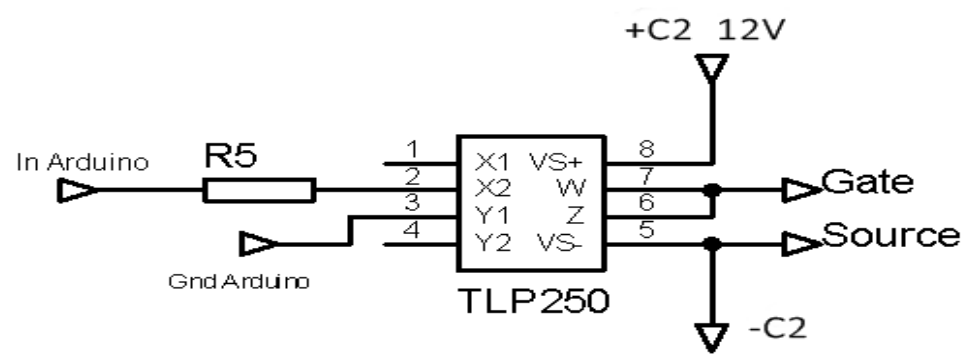

Gambar 3. Gate Driver MOSFET dengan IC TLP 250.

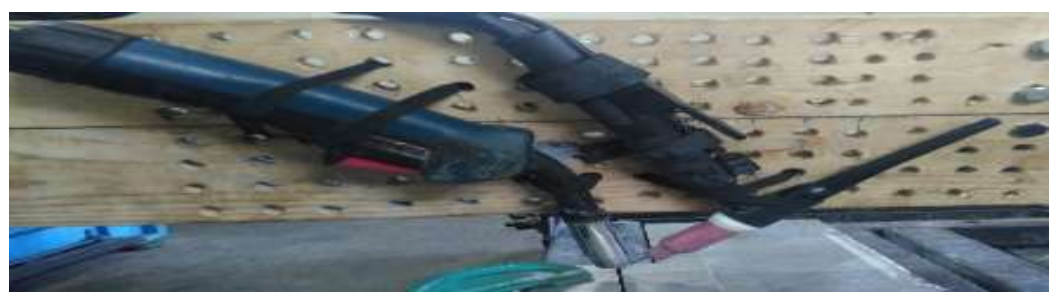

Gambar 4. Aplikasi Konstruksi Torch DE-GMAW. 
Parameter lain yang menentukan perilaku dan stabilitas busur bypass adalah sudut $\theta$ antara tungsten dan kawat las, Sudut $\theta$ dapat disesuaikan dengan mengubah posisi torch bypass dan torch GMAW. Namun, posisi torch GMAW yang bagus adalah tegak lurus terhadap benda kerja $\left(90^{\circ}\right)$, sehingga untuk merubah sudut antara torch bypass dan torch GMAW disarankan hanya mengubah posisi torch bypass dan posisi torch GMAW tetap tegak lurus terhadap benda kerja. Karena elektroda tungsten mengarah ke kolam renang las, sudut $\theta$ tidak bisa terlalu besar. Mengingat ukuran torch pemotong dan jarak d1, Sudut $\theta$ terbatas pada sekitar $60^{\circ}$. Telah dilakukan percobaan pada sudut $90^{\circ}$ antara torch bypass dan torch GMAW, namun torch bypass menabrak lelehan logam las yang telah membeku.

\subsection{Mesin Las GMAW}

Mesin las GMAW (Gas Metal Arc Welding) konvensional yang akan dimodifikasi menjadi sistem DE-GMAW memiliki spesifikasi sebagai berikut :
a. Model mesin las : GMAW.
b. Gas pelindung : Argon.
c. Input : DC / DCRP.
d. Arus : $40-250 \mathrm{~A}$.
e. Tegangan : $12-25 \mathrm{~V}$.

\subsection{Torch Las TIG}

Elektroda Bypass pada perancangan ini menggunakan Torch Las TIG yang bersifat non consumable, berfungsi sebagai alat pengambil arus pada saat proses pengelasan berlangsung. Torch Las TIG memiliki titik leleh yang tinggi dan konduktivitas listrik yang baik, torch las TIG dapat dilihat pada gambar 5 .

\subsection{Alumunium 5051}

Aluminium seri $5 \mathrm{xxx}$ merupakan jenis paduan aluminium dan magnesium, Jenis ini termasuk paduan yang tidak dapat diperlaku - panaskan, tetapi sifat dari aluminium ini mempunyai daya tahan korosi yang cukup baik, terutama korosi oleh air laut dan juga sifat mampu lasnya. Oleh karena itu paduan aluminium-magnesium banyak digunakan untuk bagian-bagian kapal, pesawat terbang, mobil, dan tangki - tangki penyimpanan gas alam. Akan tetapi dilihat dari jumlah komposisi kimia diatas kandungan magnesiumnya kurang dari $2.5 \%$ sehingga crack sensivity-nya mendekati titik puncak. Untuk mengurangi crack sensitivity tersebut dapat diatasi dengan cara penggunaan filler metal yang mengandung $(\mathrm{Mg})$ lebih tinggi seperti yang terdapat pada filler metal ER5356 yaitu $4.5-5.5 \%(\mathrm{Mg})$ atau bisa juga dengan menggunakan filler metal 4043 yang mengandung tambahan unsur (Si) sebesar 4,5 - 6\%. Jenis pengelasan yang tepat untuk aluminium seri $5 \mathrm{xxx}$ adalah dengan menggunakan las FSW (Friction Stir Welding) dikarenakan pada pengelasan MIG dan TIG masih terdapat beberapa kekurangan seperti terjadi retak panas pada hasil las dan adanya reaksi gas yang kurang ramah lingkungan.

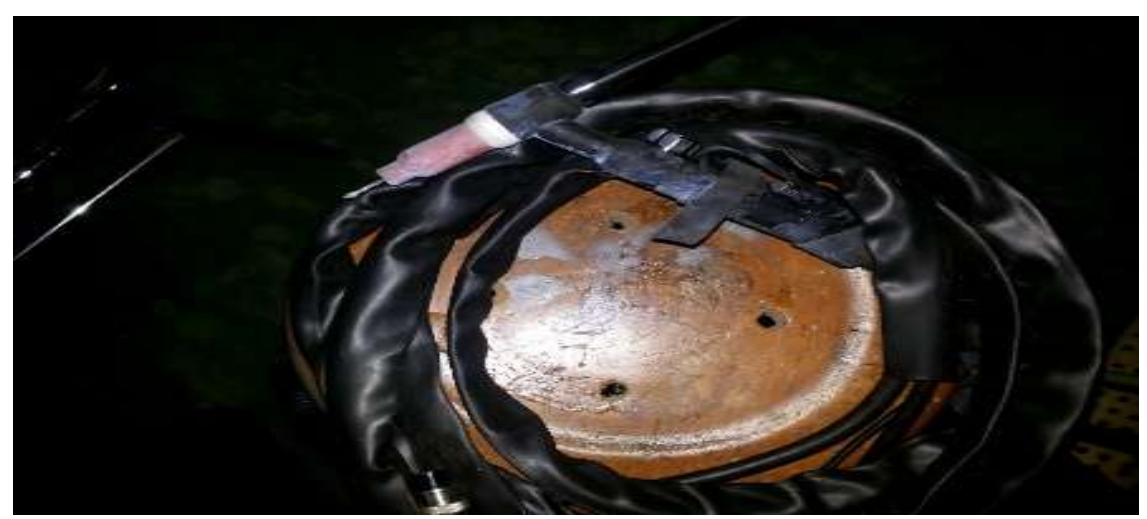

Gambar 5. Torch TIG Non Consumable. 


\subsection{Sistem}

Secara umum mesin las elektrode ganda dengan menggunakan pembatas arus untuk meningkatkan kualitas hasil pengelasan ditunjukkan pada gambar 6. Sensor ACS758 akan membaca arus yang mengalir pada Torch TIG. Arus ini akan digunakan sebagai acuan untuk mengatur besarnya arus yang mengalir pada Torch TIG sebagai media pengelasan benda kerja. Pembagian arus dilakukan oleh arduino melalui MOSFET dan rangkaian beban resistor. MOSFET akan diaktifkan dengan rangkaian gate driver yang diatur oleh arduino. LCD digunakan untuk menampilkan nilai arus yang terbaca pada saat proses pengelasan.

\section{HASIL DAN PEMBAHASAN}

\subsection{Hasil Pengujian Gagal}

Pada saat perancangan sistem DE GMAW berhasil dilakukan, maka dilakukan percobaan pengelasan. Terdapat beberapa kegagalan - kegagalan pada saat proses pengelasan, kegagalan - kegalan proses pengelasan dapat diidentifikasi melalui sifat fisik seperti dapat dilihat pada tabel 1 .
Tabel 1 menunjukkan bentuk lelehan elektroda pada sambungan las, berdasarkan bentuk lelehan tersebut dapat diketahui bahwa pengelasan menggunakan sistem kontrol DE-GMAW gagal dilakukan. gambar pada tabel diatas menunjukkan 2 kali percobaan menggunakan variasi resistor yang sama. Gambar kiri merupakan percobaan 1, gambar kanan menunjukkan percobaan 2. Lelehan pada sambungan las yang menumpuk dan terputus - putus disebabkan oleh gangguan tungsten torch TIG, karena torch TIG tidak mengambil arus maka tungsten menjadi penghalang proses pelelehan elektroda pada sambungan las.

Kegagalan proses pengelasan menggunakan sistem kontrol DE-GMAW dapat juga diidentifikasi melalui nilai yang terbaca pada sensor arus, seperti yang dapat dilihat pada gambar 7 arus total pengelasan berkisar antara $90-105 \mathrm{~A}$, itu berarti arus tidak terpotong oleh sistem kontrol DEGMAW dan tidak arus yang mengalir pada sistem kontrol.

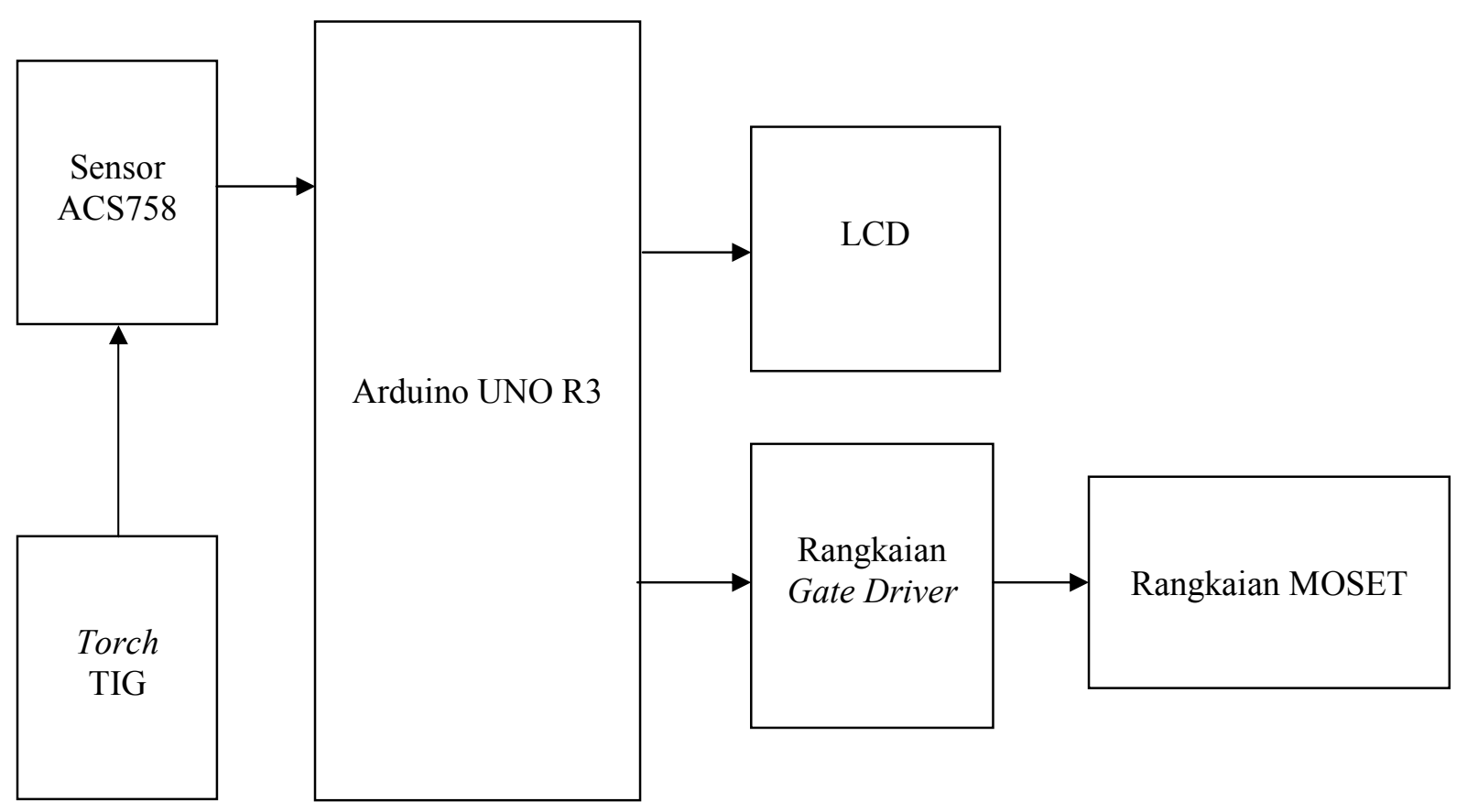

Gambar 6. Blok Diagram Sistem. 
Tabel 1. Percobaan Las Gagal Menggunakan Sistem Kontrol DE-GMAW

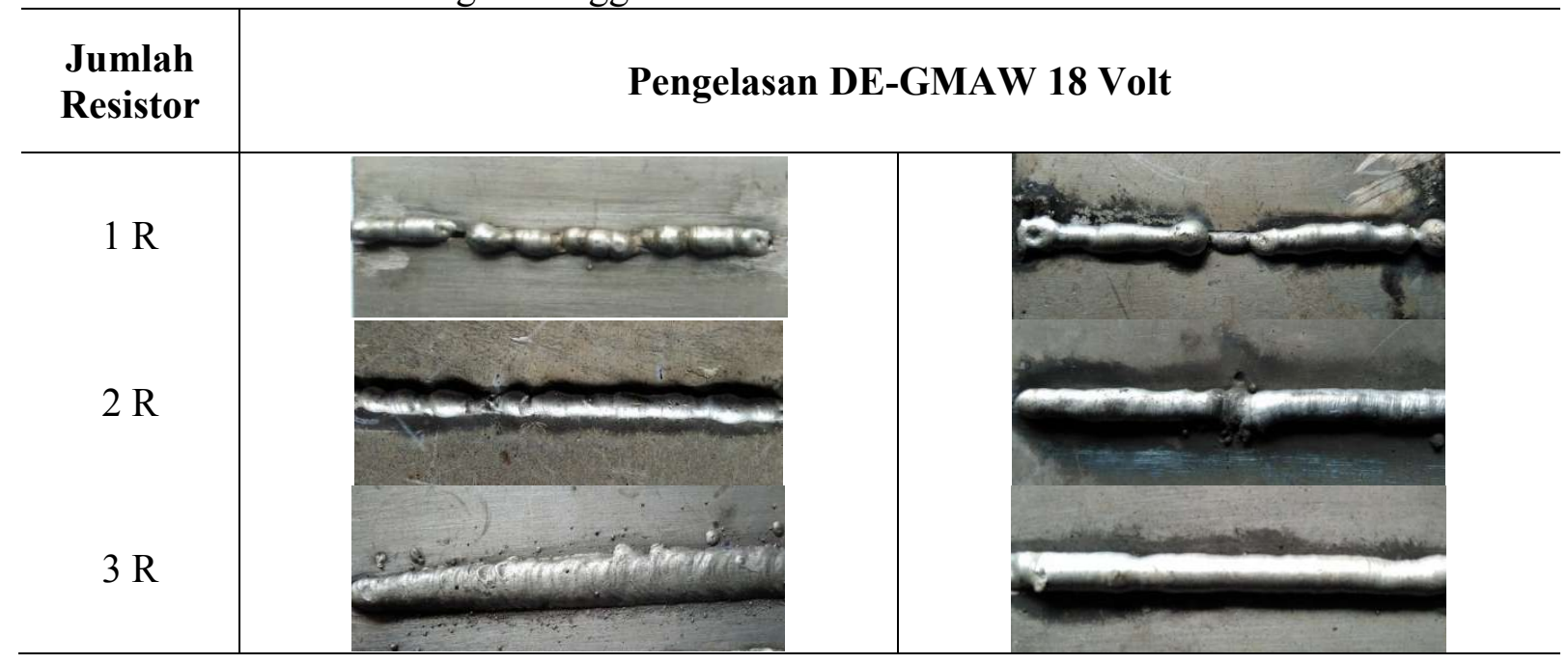

Tabel 2. Tegangan Input dan Output Gate Driver

\begin{tabular}{c|c|c}
\hline Gate Driver & Tegangan Input & Tegangan Output \\
\hline 1 & $12 \mathrm{~V}$ & $12.27 \mathrm{~V}$ \\
2 & $12 \mathrm{~V}$ & $12.36 \mathrm{~V}$ \\
3 & $12 \mathrm{~V}$ & $12.32 \mathrm{~V}$ \\
\hline
\end{tabular}

Arus Pengelasan

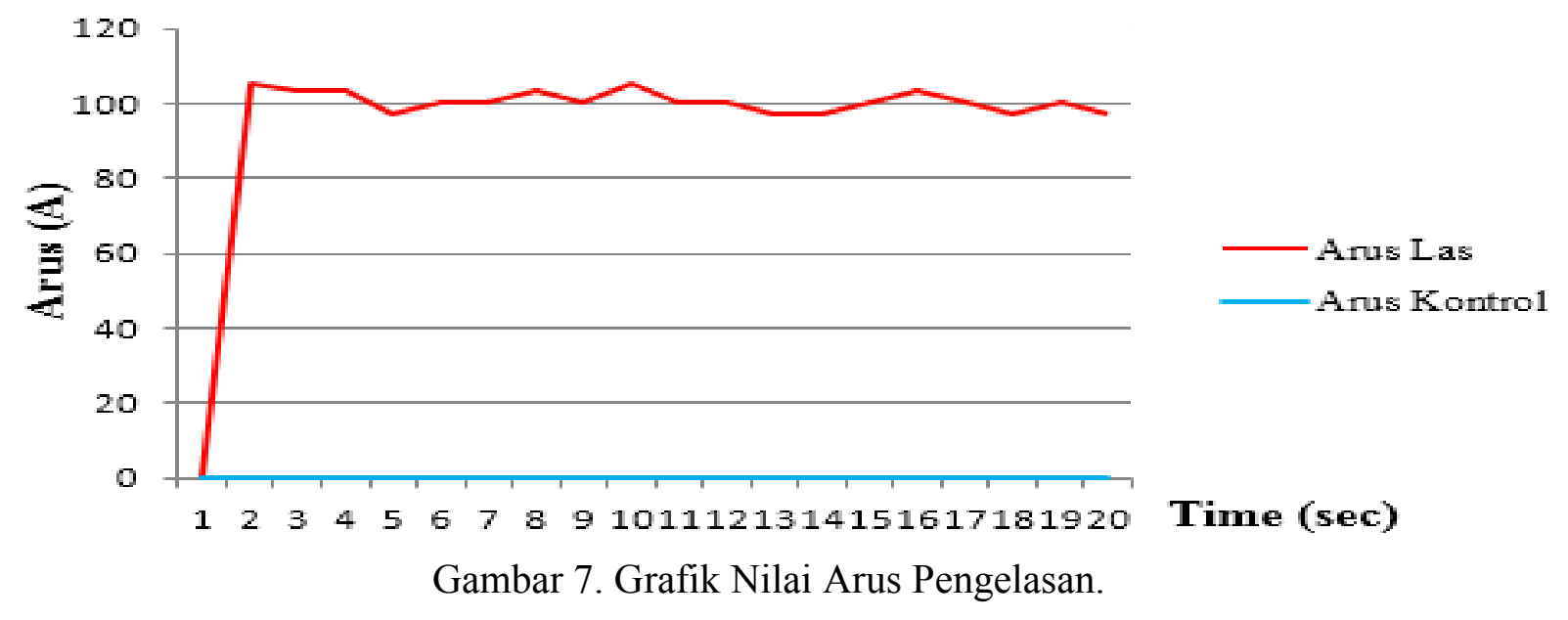

\subsection{Hasil Pengujian Berhasil}

\subsubsection{Pengujian Rangkaian Gate Driver}

Dalam pengujian ini, tiga unit rangkaian gate driver diberi input tegangan $+12 \mathrm{~V}$ dari adaptor catudaya DC. Tegangan output dari gate driver ini kemudian di-input-kan ke kaki gate pada MOSFET dengan besar tegangan suplai minimum $+10 \mathrm{~V}$.
Gate driver akan menghasilkan tegangan output ketika mendapat sinyal input dari mikrokontroler. Sementara itu sinyal yang di-input-kan pada rangkaian gate driver dibangkitkan dari output digital mikrokontroler Arduino UNO, dengan tegangan $3.3 \mathrm{~V}-5 \mathrm{~V}$. Variasi tegangan output dari ketiga rangkaian gate driver ditunjukkan pada tabel 2 . 
Tabel 3. Tegangan Gate to Source MOSFET

\begin{tabular}{l|c|c}
\hline No & MOSFET & Tegangan \\
\hline 1 & 1 & $12.27 \mathrm{~V}$ \\
2 & 2 & $12.36 \mathrm{~V}$ \\
3 & 3 & $12.32 \mathrm{~V}$ \\
\hline
\end{tabular}

Tabel 4. Nilai Arus Pada Saat Proses Pengelasan Dengan Voltase 18 V

\begin{tabular}{c|c|c}
\hline Waktu (s) & Nilai Analog & Nilai Arus \\
\hline 1 & 0 & 0 \\
2 & 726.00 & 105.509 \\
3 & 722.00 & 103.564 \\
4 & 722.00 & 103.564 \\
5 & 709.00 & 97.243 \\
6 & 716.00 & 100.647 \\
7 & 715.00 & 100.161 \\
8 & 722.00 & 103.564 \\
9 & 716.00 & 100.647 \\
10 & 726.00 & 105.509 \\
\hline
\end{tabular}

\subsubsection{Pengujian Rangkaian MOSFET}

Pengujian MOSFET dapat menggunakan sebuah multimeter digital untuk mengukur atau mengujinya. Pengujian dilakukan untuk mengetahui apakah MOSFET aktif atau tidak ketika mendapat tegangan input dari gate driver. Pengujian mosfet menggunakan multimeter digital juga dapat untuk mengetahui sebuah MOSFET mengalami kerusakan atau tidak, meskipun menggunakan cara yang cukup sederhana namun cukup memadai untuk mengetahui baik atau rusaknya MOSFET tersebut. Variasi tegangan gate to source MOSFET dapat dilihat pada tabel 3 .

\subsubsection{Pengujian Sensor Arus ACS 758}

Pada perancangan ini sensor arus yang dipakai adalah sensor arus ACS758 dengan kapasitas 200 A. Sistem kerja alat sensor ini adalah dengan hall effect yang memanfaatkan medan listrik dari arus DC. Dari Tegangan DC tersebut merupakan data analog dari sensor yang akan dirubah ke bentuk digital pada mikrokontroler yang disebut ADC (Analog to Digital Converter). Nilai output yang dihasilkan oleh sensor arus ACS758 merupakan nilai arus yang terbaca pada logam dasar las. 
Tabel 5. Hasil Pengelasan Dengan Kontrol DE-GMAW

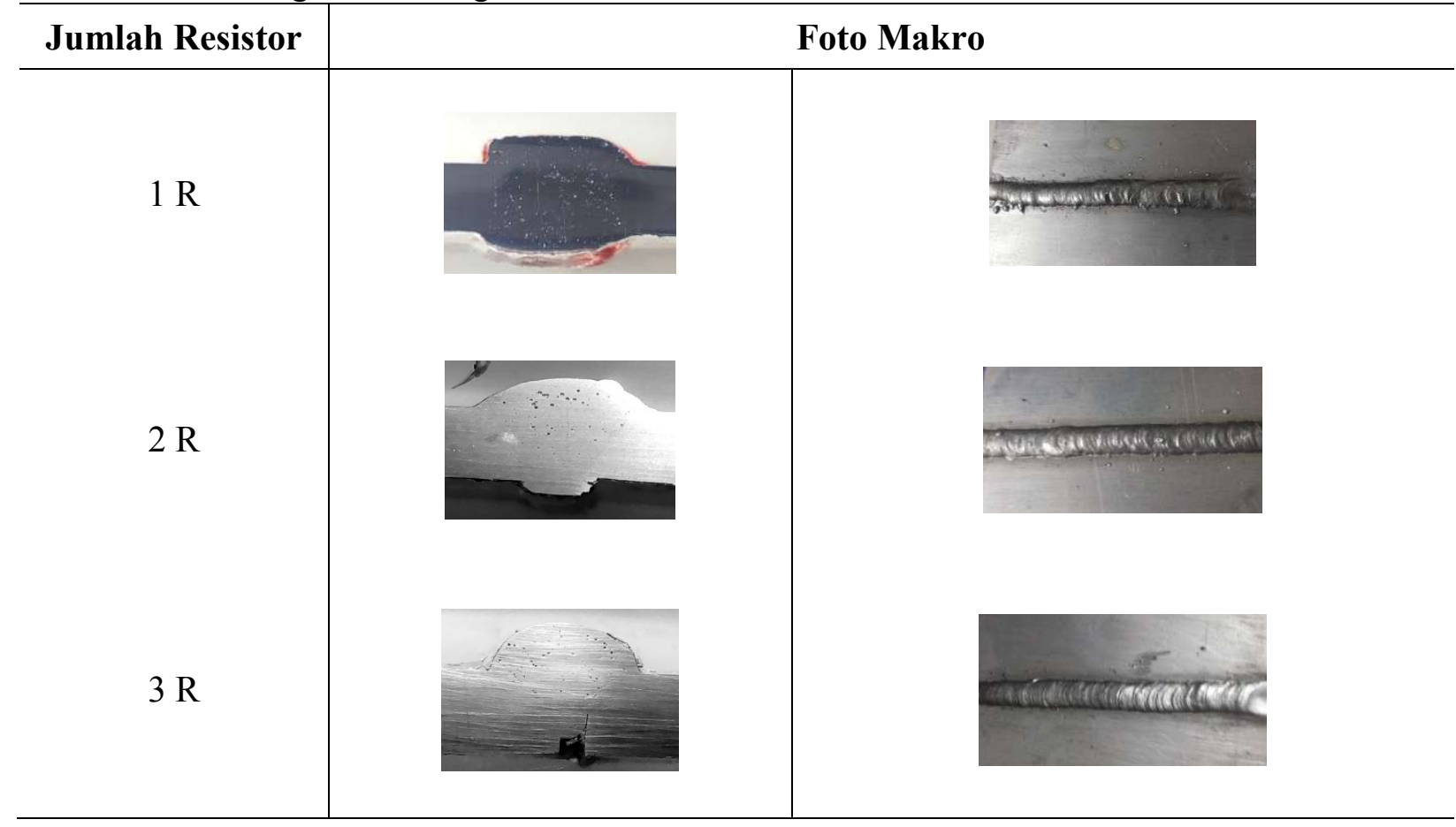

Nilai Arus Pengelasan dengan Variasi R

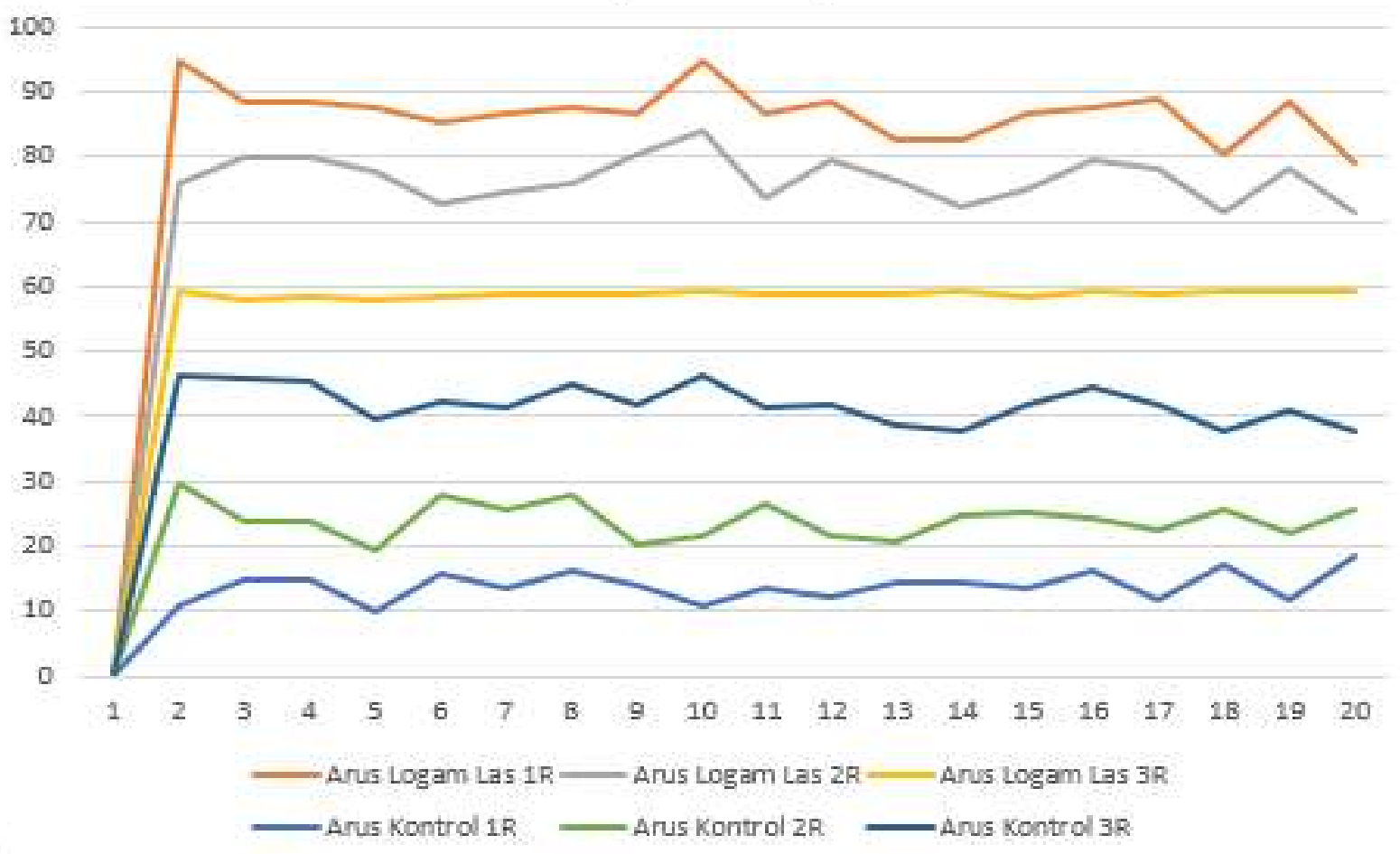

Gambar 8. Nilai Arus Pengelasan Dengan Variasi R. 
Sensor arus menggunakan rangkaian tambahan low pas filter untuk mencegah terjadinya riak arus. Nilai arus yang terbaca pada saat proses pengelasan dengan tegangan 18 Volt tanpa menggunakan sistem kontrol arus ditunjukkan pada tabel 4 .

\subsubsection{Pengujian Pengelasan Menggunakan Sistem Kontrol DE-GMAW}

Sistem DE-GMAW lengkap dirancang dengan power supply (GMAW), torch GMAW, torch GTAW, dan 3 resistor masing masing memiliki hambatan 1,2 ohm dan dikontrol oleh 3 MOSFET. Kedua torch terlindung dengan argon murni. Kestabilan alat ini sangat tergantung pada parameter parameter proses pengelasan yang telah dijelaskan pada halaman sebelumnya. Parameter - parameter tersebut dapat digunakan sebagai acuan, agar alat kontrol arus yang dirancang dapat bekerja dengan stabil. Parameter yang sangat mempengaruhi proses stabilitas sistem kontrol adalah hubungan antara torch mesin las GMAW dengan torch TIG pada sistem kontrol. Hasil pengelasan dengan kontrol DE-GMAW ditunjukkan pada tabel 5 .

Tabel 5 menunjukan hasil pengelasan menggunakan sistem kontrol DE-GMAW menggunakan variasi 1 resistor, 2 resitor, 3 resitor. Pengelasan menggunakan 1 resistor lelehan yang terbentuk padat, lelehan logam las terisi sempurna, kawah las yang tebentuk sedang atau tidal terlalu lebar. Pengelasan menggunakan variasi 2 resistor kawah hasil pengelasan yang terbentuk kecil, lelehan las terisi sempurna.
Pengelasan menngunakan variasi 3 resistor kawah hasil las yang terbentuk sangat kecil, lelehan logam pengisi tidak terisi sempurna, hal ini sangat berpengaruh pada kekuatan mekanik hasil pengelasan. Nilai arus yang mengalir saat pengelasan dengan kontrol DE-GMAW ditunjukkan pada gambar 8 .

Dari gambar 8 menunjukkan arus yang dikontrol dengan $1 \mathrm{R}$ berkisar antara $15-18$ A, sementara arus maksimal yang izinkan melewati 1 resistor adalah $15 \mathrm{~A}$. Hal ini disebabkan karena resistor memiliki toleransi nilai hambatan yang berbeda beda. Arus yang dikontrol dengan $1 \mathrm{R}$ berkisar antara $20-25 \mathrm{~A}$, sementara arus yang diharapkan dapat terkontrol adalah 30 A. Arus yang dikontrol masih belum sesuai dengan yang diharapkan, gelombang arus pengelasan juga tinggi. Namun jika dibandingkan dengan percobaan pengelasan DE-GMAW 1 resistor, arus yang dipotong lebih tinggi.

Sehingga panas pada logam dasar dapat berkurang, meskipun tidak signifikan. Arus yang mengalir pada sitem kontrol dengan 3 $\mathrm{R}$ adalah $45 \mathrm{~A}$. Arus logam dasar sangat konstan, hal ini disebabkan oleh kecilnya hambatan ketika menggunakan 3 resistor. Berdasarkan hasil dari ketiga percobaan pengelasan yang telah dilakukan menggunakan sistem kontrol dengan variasi resistor yang berbeda - beda pada tegangan $18 \mathrm{~V}$, arus yang dapat dikontrol dengan baik yaitu menggunakan 3 resistor namun belum tentu sifat mekaniknya bagus. Hal ini disebabkan semakin tingginya nilai arus yang dikontrol mengakibatkan kurangnya masukan panas pada logam dasar. 


\section{KESIMPULAN}

Sistem GMAW double - elektroda dikembangkan dengan menambahkan elektroda tungsten non - consumable dalam sistem GMAW konvensional untuk membentuk loop bypass. Kondisi untuk membangun dan memelihara proses yang stabil diperoleh melalui eksperimen. Sistem ini digunakan kelompok daya resistor yang disesuaikan dan dikendalikan oleh MOSFET untuk mendapatkan variasi kontrol arus yang berbeda.

Sistem kontrol dapat bekerja sesuai dengan yang diharapkan, arus pada logam dasaar dapat dikurangi sehingga masukan panas pada logam dasar las juga berkurang. Parameter yang mempengaruhi stabilitas sistem kontrol adalah Elektroda Bypass, Jarak Tungsten ke Elektroda Las, Jarak Tungsten ke Benda kerja, Jarak Tabung Torch GMAW ke Benda kerja, Sudut antara Tungsten dan Kawat Las. Faktor - faktor yang menyebabkan kegagalan - kegagalan proses pengelasan DE-GMAW disebabkan oleh Jarak torch TIG dengan torch GMAW yang tidak sesuai dengan paramater dan kerusakan-kerusakan komponen.

\section{DAFTAR PUSTAKA}

Fitriadi and Hamid, M.I. Desain Rangkaian Gate-Driver Untuk Konverter yang Bekerja Dengan Voltage Mode Control. Jurnal Nasional Teknik Elektro. 5(2): 175-180,. 2016.

Fitriandi, A., dkk. Rancang Bangun Alat Monitoring Arus dan Tegangan Berbasis Mikrokontroler dengan SMS Gateway. Jurnal Rekayasa dan Teknologi Elektro. 10(2): 87-98., 2016.
Li, K. H and Zhang, Y. Metal Transfer in Double-Electrode Gas Metal Arc Welding. Welding Jurnal. 1-20., 2007.

Li, K.H and Zhang, Y. Consumable Double Electrode GMAW. Welding Journal. 87: 11-17., 2008.

Li, K.H and Wu, C. Mechanism of Metal Transfer in DE-GMAW. J. Mater. Sci. Technol. 25(3): 415-418., 2009.

Li, K.H., dkk. Double-Electrode GMAW Process and Control. Welding. Journal. 86: 231-237., 2007.

Li, Y., dkk. Double-Electrode Arc Welding Process: Principle, Variants, Control and Developments. Journal of Manufacturing Processes. 16(1): 93-108., 2014.

Liu, X. Dual Bypass Gas Metal Arc Welding Process and Control. Disertasi. University of Kentucky., 2008.

Maulana, E. Teori Dasar Mosfet. http://maulana.lecture.ub.ac.id/files /2014/03/Teori-Dasar-MOSFETMetal-Oxide-Semiconductor-FieldEffect-Transistor.pdf. (Diakses pada tanggal 29 Maret 2014).

Melipurbowo, B.G. Pengukuran Daya Listrik Real Time Dengan Menggunakan Sensor Arus Acs.712. ORBITH. 12 (1): 17-23., 2016.

Muku, I. D. M. K. Kekuatan Sambungan Las Aluminium Seri 1100 dengan Variasi Kuat Arus Listrik Pada Proses Las Metal Inert Gas (MIG). Jurnal Ilmiah Teknik Mesin Cakra M. 3 (1): 11-17., .2009.

Mulyono, D.P. Rangkaian Mekanik Bootstrap untuk Meningkatkan Kinerja Gate Drive Mosfet. Universitas Islam Indonesia, Yogyakarta., 2017. 
Prawira, M.Z., dkk. Pengaruh Perbedaan Suhu Terhadap Kekuatan Impact Alumunium 5083 Hasil Pengelasan Tungsten Inert Gas. Jurnal Teknik Perkapalan. 3 : 362-370., 2015.

Purwaningrum, Y. Effects of Root Opening on Physical and Mechanical Properties of the Double Side Welded of Ship Materials. Research Gate.

https://www.researchgate.net/public ation/302976686 (diakses pada tanggal 26 October 2016).

Riyan, F. Pengaruh Jenis Elektroda Dan Arus Pengelasan Terhadap Kekuatan Tarik Pada Pengelasan Baja St 41 Menggunakan Las Smaw. Jurnal Nasional Teknik Mesin. 1 -10., 2017.

Santoso, T.B., dkk. Pengaruh Kuat Arus Listrik Pengelasan Terhadap Kekuatan Tarik Dan Struktur Mikro Las Smaw Dengan Elektroda E7016. Jurnal Teknik Mesin. 5664., 2015.

Wiryosumarto, dkk. Teknologi Pengelasan Logam. Jakarta : PT. Pradnya paramitha., 1994. 